\title{
Graphene Oxide/Multilayer-Graphene Synthesized from Electrochemically Exfoliated Graphite and Its Influence on Mechanical Behavior of Polyurethane Composites
}

\author{
L. M. Flores-Vélez¹, 0. Domínguez² \\ ${ }^{1}$ Faculty of Chemistry, UASLP, San Luis Potosí, México \\ ${ }^{2}$ Institute of Metallurgy, UASLP, San Luis Potosí, México \\ Email: nanochimica@yahoo.com
}

How to cite this paper: Flores-Vélez, L.M. and Domínguez, O. (2018) Graphene Oxide/Multilayer-Graphene Synthesized from Electrochemically Exfoliated Graphite and Its Influence on Mechanical Behavior of Polyurethane Composites. Materials Sciences and Applications, 9, 565-575.

https://doi.org/10.4236/msa.2018.97041

Received: April 4, 2018

Accepted: June 9, 2018

Published: June 12, 2018

Copyright $\odot 2018$ by authors and Scientific Research Publishing Inc. This work is licensed under the Creative Commons Attribution International License (CC BY 4.0).

http://creativecommons.org/licenses/by/4.0/

\begin{abstract}
Graphene Oxide/Multilayer-Graphene (GO-MG) flakes were obtained using an electrochemically exfoliated graphite (GR) electrode from secondary steel-making industry performed in a two-electrode system using tungsten as the counter electrode and GR as the working electrode. The exfoliated GO-MG flakes were processed and incorporated in an elastomeric polyurethane (PU) matrix. The mechanical properties of the PU/GO-MG composites were evaluated and compared with equivalent composites made of PU/GR powder. From experimental data analysis it was concluded that GO-MG flakes were approximately composed of $67 \mathrm{wt} \% \mathrm{GO}$ and $33 \mathrm{wt} \% \mathrm{MG}$. The number of layers in the graphene flakes was estimated to be between 2 and 5 sheets. PU showed a breaking stress of $570 \mathrm{kPa}$, while the PU/20wt\% GR attained a maximum stress of $750 \mathrm{kPa}$ as compared to $\mathrm{PU} / 10 \mathrm{wt} \% \mathrm{GO}-\mathrm{MF}$ composite exhibiting a breaking stress of $1060 \mathrm{kPa}$.
\end{abstract}

\section{Keywords}

Electrochemical Exfoliation, Graphene Oxide, Nanocomposites, Polyurethane

\section{Introduction}

Since the last century, a large amount of graphite (GR) and carbon products are now synthetic and these products have been improved continuously [1]. Synthetic graphitic products are manufactured by a compaction process mixing carbon and organic binders followed by a graphitizing treatment, leading to commercial products such as the electrodes for secondary steel-making industry. 
Since the discovery and characterization of graphene (G) in 2004 [2], research has been directed to find new manufacturing techniques [3] [4] [5] to promote industrial applications of graphene together with graphene oxide (GO). Graphene films grown by chemical vapor deposition (CVD) exhibit high quality but are not suitable for large-scale production [6] [7]. Chemical exfoliation methods based on the Hummers' method promoting graphite oxidation to obtain graphene oxide (GO) followed by chemical or thermal reduction may have the advantages of low-cost fabrication process [8] [9]. Electrochemical exfoliation of high-quality graphite in aqueous solutions has led to graphene and/or graphene oxide sheets depending on the experimental parameters [10] [11] [12]. Besides, at present industrial research is looking for large-scale polymer/graphene-product nanocomposites which promise to attain materials with better electronic, thermal and/or mechanical properties [13] [14]. In the present preliminary work, graphene oxide/multilayer-graphene (GO-MG) flakes were obtained by electrochemical exfoliation of industrial steel-making graphite electrodes following the procedures reported in the literature [11] [15] with some slight modifications. The exfoliated GO-MG flakes were processed to finally be incorporated in a domestic isocyanate/polyol commercial system required to achieve the corresponding elastomeric polyurethane (PU) matrix. The mechanical properties of the PU/GO-MG composites were evaluated and compared with equivalent composites made of PU/GR powder to exhibit the enhanced chemical bonding between GO-MF flakes and polyurethane chains.

\section{Experimental Procedure}

\subsection{Apparatus}

Transmission electron microscopy (TEM) and X-ray diffraction (XRD) measurements were performed on powder samples obtained from the electrochemical exfoliation of graphite. The TEM measurements were carried out using an electron microscope JEOL (Jem-1400) in bright field mode at $100 \mathrm{kV}$. The powder XRD data were collected with BRUKER (D8 Advance) diffractometer in a Bragg-Brentano configuration using $\mathrm{Cu}$-sealed tube $\left(\mathrm{CuK}_{\mathrm{a}}=0.15418 \mathrm{~nm}\right)$ operating at $40 \mathrm{kV}$ and $30 \mathrm{~mA}$. Measurements were performed in the scattering $2 \theta$ range of $5^{\circ}$ to $60^{\circ}$ with a step size of $0.01^{\circ}$ and counting rate of $2 \mathrm{~s} / \mathrm{step}$. UV-Vis absorption spectra were recorded on a PERKIN-ELMER UV/Vis (Lambda-25) spectrometer to gain further information into the quality of electrochemically prepared GO-MG flakes. Raman spectroscopy (RS) was carried out using RENISHAW system with an excitation laser source of $532 \mathrm{~nm}$ and power below $0.1 \mathrm{~mW}$ on the sample to avoid induced laser heating. To evaluate the mechanical properties, tension test was performed using a PHYSICAL TEST SOLUTIONS (MMD-30k) universal material testing machine using a cross-head speed of $1 \mathrm{~mm} / \mathrm{min}$ at room temperature.

\subsection{Materials Manufacture}

Exfoliated graphene oxide/multilayer-graphene (GO-MF) flakes were obtained 
by electrochemical exfoliation of industrial graphite performed in a two-electrode system using tungsten $(99.5 \% \mathrm{~W})$ as the counter electrode and graphite as the working electrode. The separation between the cathode and the anode was maintained at $3 \mathrm{~cm}$. Usually there is the presence of impurities on industrial graphite-like $\mathrm{Fe}, \mathrm{Co}, \mathrm{Cu}$ and $\mathrm{Ni}$ [16], consequently in aqueous acid conditions the cationic species should remain dissolved, so the chosen electrolyte solution was prepared from concentrated sulfuric acid $\left(\mathrm{H}_{2} \mathrm{SO}_{4}\right)$ and deionized water $(\mathrm{pH}$ adjusted to $\approx 1.50$ ). A direct $\mathrm{DC}$ voltage bias of $+2.5 \mathrm{~V}$ was first applied to the graphite for 1 hour to cause soft intercalation of the $\mathrm{SO}_{4}{ }^{2-}$ ions in the graphite layers [3] [11], and at this conditions, the graphite electrode remained solid. Then the voltage bias was increased to $+6 \mathrm{~V}$ and the graphite electrode started to dissociate in small flakes distributing all over the solution. The experimental setup for electrochemical exfoliation of graphite electrode is shown in Figure 1(a) and the final electrochemical exfoliated product after 4 hours is also shown in Figure 1(b). Test specimens for evaluation of the tensile properties of elastomeric PU/GO-MG composites were obtained washing and drying the GO-MG flakes, then dispersing the product in 1,4-butanediol, drying once again to mix it with the polyol compound, then the slurry was added to the isocyanate compound and finally cast to the molds. Figure 2 illustrates the size and shape of the samples used to determine the mechanical behavior of the elastomeric PU composites filled with different concentrations of GR and GO-MG.

\section{Results and Discussion}

Figure 3 illustrates the morphology of the GO-MG flakes which were observed by transmission electron microscopy (TEM). The TEM images revealed two different type of morphologies, one disordered with scrolls and wrinkles (Figure $3(a))$ and the other with a transparent and sheet-like structure (Figure 3(b)).

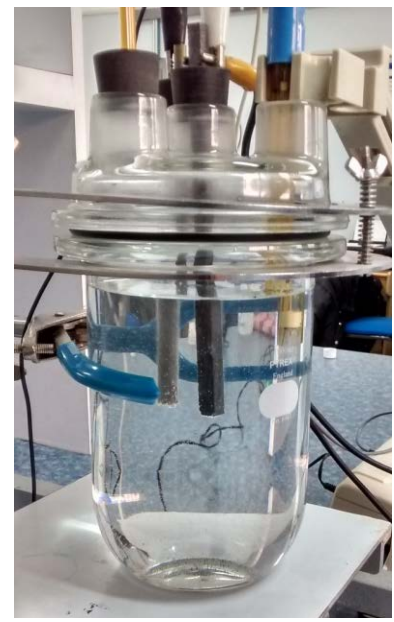

(a)

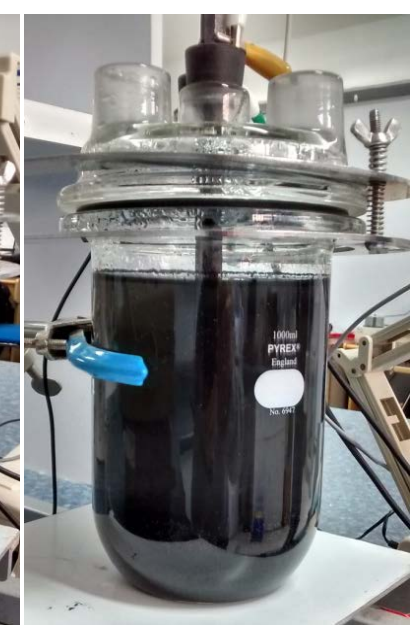

(b)

Figure 1. Photographs of the electrochemical exfoliation of graphite. (a) System at a voltage bias of $+2.5 \mathrm{~V}$; (b) System after 4 hours at a voltage bias of $+6 \mathrm{~V}$. 


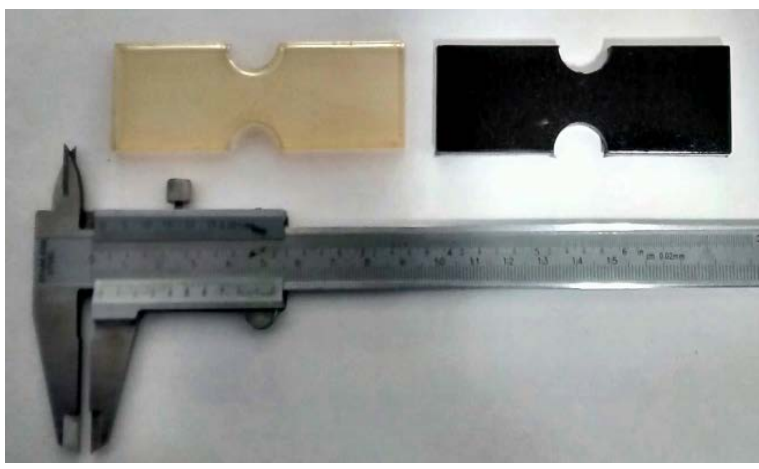

Figure 2. Photographe showing the shape and size of the tensile elastomeric PU composite samples fabricated without (white) and with $10 \mathrm{wt} \%$ GO-MG (black).

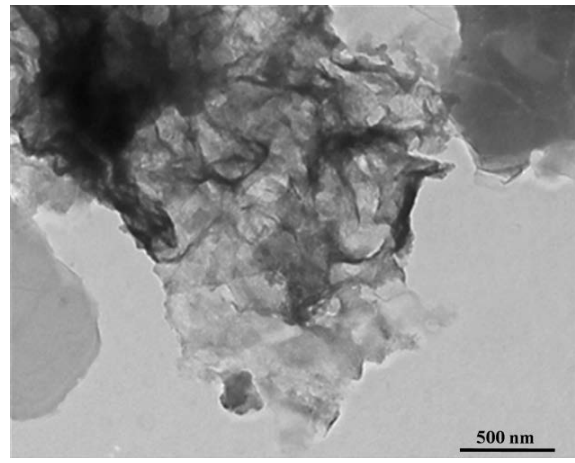

(a)

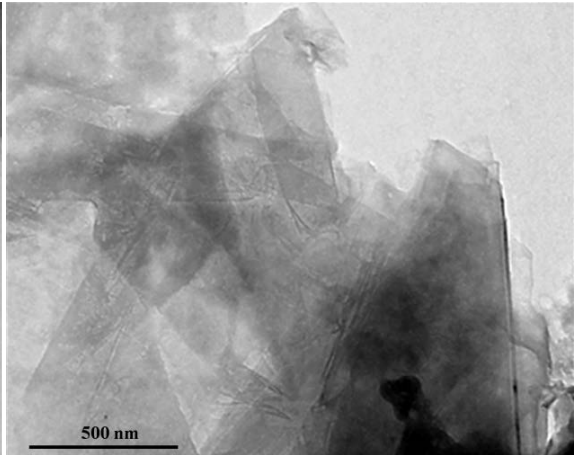

(b)

Figure 3. TEM bright field images obtained from the electrochemical exfoliation of graphite. (a) Graphene oxide (GO); (b) Multilayer graphene (MG).

Both type of flakes remained stable under the electron beam. In general, graphene oxide (GO) has been assigned to the morphology having scrolls and wrinkles while the sheet-like morphology has usually been assigned to multilayer graphene structure (MG) [17] [18] [19].

To corroborate the presence of both GO and MG compounds, XRD were performed on exfoliated flakes. Figure 4 clearly shows the difference between the XRD patterns of the graphite powder obtained from mechanical grinding the GR electrode and the flakes obtained from electrochemical exfoliation of the GR electrode. Figure 4 indicates that graphite electrode is highly crystalline and the most intense peak is the one associated to the (002) crystallographic planes of graphite (JCPDS 41-1487). On the other hand, the XRD pattern of the exfoliated graphite in Figure 4 shows two broad peaks at $2 \theta=11.28^{\circ}$ and $2 \theta=26.19^{\circ}$. The first peak at $11.28^{\circ}$ has frequently been associated to the presence of graphene oxide [17] [18] [19] [20] [21] as a consequence of the intercalation of different functional groups. The second broad peak should correspond to the (002) graphite planes, but the usually interlayer distance of $0.337 \mathrm{~nm}$ found in Figure 4 for graphite powder, in the case of GO-MG flakes seems to be slightly larger than that of the d-spacing of bulk graphite. 


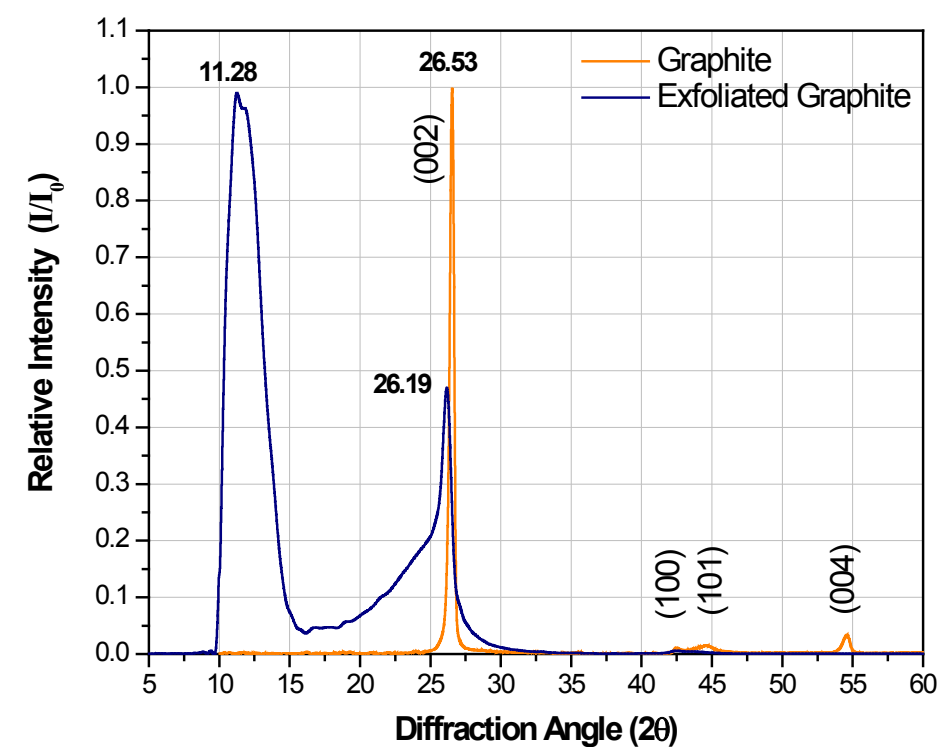

Figure 4. XRD patterns obtained from graphite electrode powder and GO-MG exfoliated flakes.

$\mathrm{UV}$-Vis spectra of aqueous electrochemical exfoliated graphite dispersions were used to determined the presence of $\mathrm{C}=\mathrm{C}$ and $\mathrm{C}-\mathrm{O}$ bonding. The spectrum obtained by UV-Vis spectroscopy of the electrochemically exfoliated graphite is in agreement with the previously graphene oxide reported results [22] [23] [24] [25], where an absorption peak appears at about $230 \mathrm{~nm}$ and a broad peak at approximately $290-310 \mathrm{~nm}$ as shown in Figure 5. The absorption peak at $230 \mathrm{~nm}$ has been assigned to the $\pi \rightarrow \pi^{*}$ transition of the $\mathrm{C}=\mathrm{C}$ bonds by other authors [22] [23]. Then, the present assumption of the absorption peak observed at $226 \mathrm{~nm}$ to the same $\pi \rightarrow \pi^{*}$ transition seems quite reasonable. On the other hand as in previous works [17] [24] [25], it is possible to assign the broad peak observed at $305 \mathrm{~nm}$ to the $\mathrm{n} \rightarrow \pi^{*}$ transitions due to the presence of $\mathrm{C}-\mathrm{O}$ - $\mathrm{C}$ or $\mathrm{C}-\mathrm{OOH}$ bonding, usually reported for graphene oxide. On the other hand, there is experimental evidence suggesting that $\pi \rightarrow \pi^{*}$ transition shifts to higher wavelength (red-shift), displaying the peak at about $250 \mathrm{~nm}$ when graphene is present [22] [23]. Because the peak observed at $226 \mathrm{~nm}$ in Figure 5 is quite wide, there was no possibility to discern by this technique the presence of graphene in the GO-MG flakes.

Also, Raman spectroscopy (RS) was used to know about structural changes occurred during the electrochemical exfoliation of graphite, mainly because RS is a sensitive technique to characterize disorder in $\mathrm{sp}^{2}$ carbon materials. The G-band observed in Figure 6 (at $1585 \mathrm{~cm}^{-1}$ ) arises from the stretching of the $\mathrm{C}-$ $\mathrm{C}$ bond in graphitic materials and is common to all $\mathrm{sp}^{2}$ carbon systems.

The peak at $1355 \mathrm{~cm}^{-1}$ know as the D-band represents the resonance of aromatic rings arising due to defects in the structure and its presence suggest the existence of GO [26]. On the other hand in Figure 6, the 2D peak at around $2700 \mathrm{~cm}^{-1}$ is active in the absence of any defects and the peak shifts with the 
number of graphene layers, becoming similar to that of graphite if there is more than 10 layers of graphene, in which case the peak appears at $2730 \mathrm{~cm}^{-1}$ [26] [27]. Consequently, from reported experimental data [27] the number of layers in the graphene flakes should be approximately between 2 and 5 in our samples. Then, all experimental data indicated the presence of both, graphene oxide and multilayer-graphene compounds in the electrochemically exfoliated graphite flakes. From XRD peak analysis using the Rietveld refinement method and considering from Figure 4 that only was possible to assign the presence of two different structures, it was concluded that GO-MG flakes were approximately composed of $67 \mathrm{wt} \% \mathrm{GO}$ and $33 \mathrm{wt} \% \mathrm{MG}$. If there are other compounds in the GO-MG flakes, they should be below the detection limit of the XRD technique.

Figure 7 shows a microphotograph of the employed graphite particles together with the tensile properties of the PU/GR composites with different graphite powder content. In this case, the maximum attained strength was of $750 \mathrm{kPa}$ and corresponds to $20 \mathrm{wt} \%$ of graphite (PU/20GR). On the other hand, Figure 8(a) shows the tensile properties of the PU/GO-MG composites with different filler content. From stress-strain curves, it can be seen a remarkable difference in the mechanical behavior between GR and GO-MG composites. In both cases, it can be seen that although the elongation at break decreases with increasing filler content, the overall elongation of the composite materials still is significant. Besides, Figure 7 strongly suggests that the reinforcement contribution of graphite is not as effective as the one observed in Figure 8(a) for graphene oxide/multilayer-graphene (GO-MG). The relationship between the breaking stress of composites and type of filler content is shown in Figure 8(b). The pure $\mathrm{PU}$ showed a breaking stress of $570 \mathrm{kPa}$ as compared to PU/10GO-MF composite exhibiting a breaking stress of $1060 \mathrm{kPa}$.

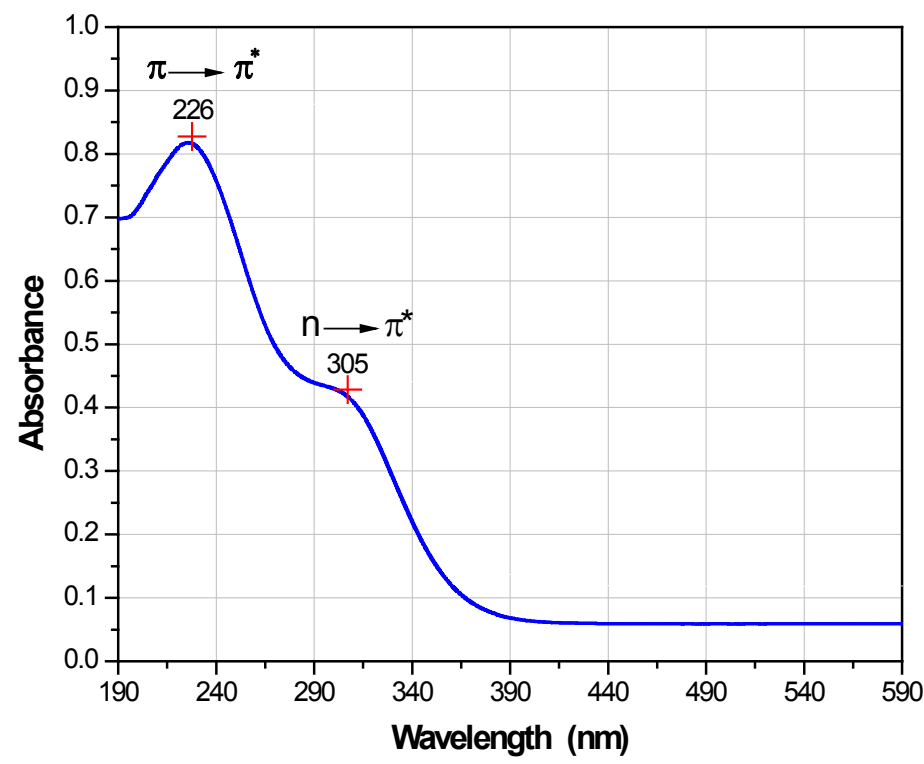

Figure 5. UV-Vis absorption spectrum of the electrochemically exfoliated graphite solution in a quartz cuvette. 


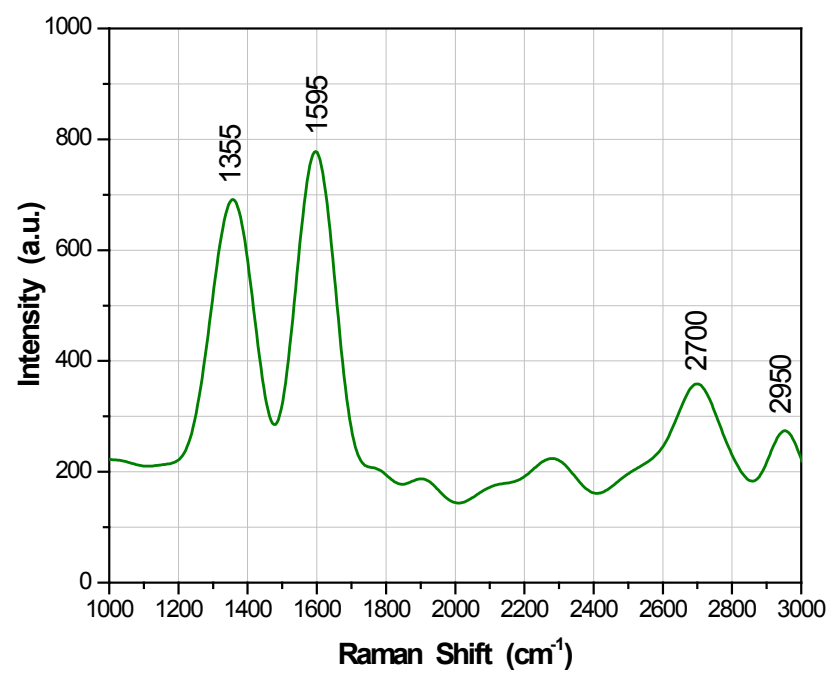

Figure 6. Raman spectrum of the GO-MG flakes showing the $\mathrm{G}$ $\left(1355 \mathrm{~cm}^{-1}\right), \mathrm{D}\left(1585 \mathrm{~cm}^{-1}\right)$ and $2 \mathrm{D}\left(2700 \mathrm{~cm}^{-1}\right)$ bands.

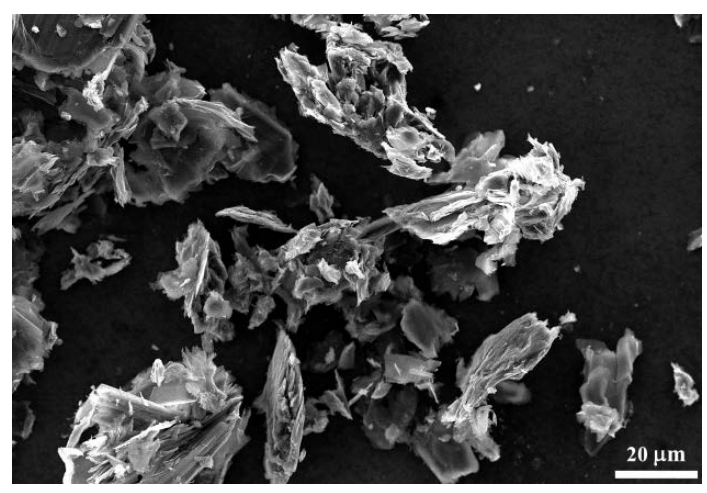

(a)

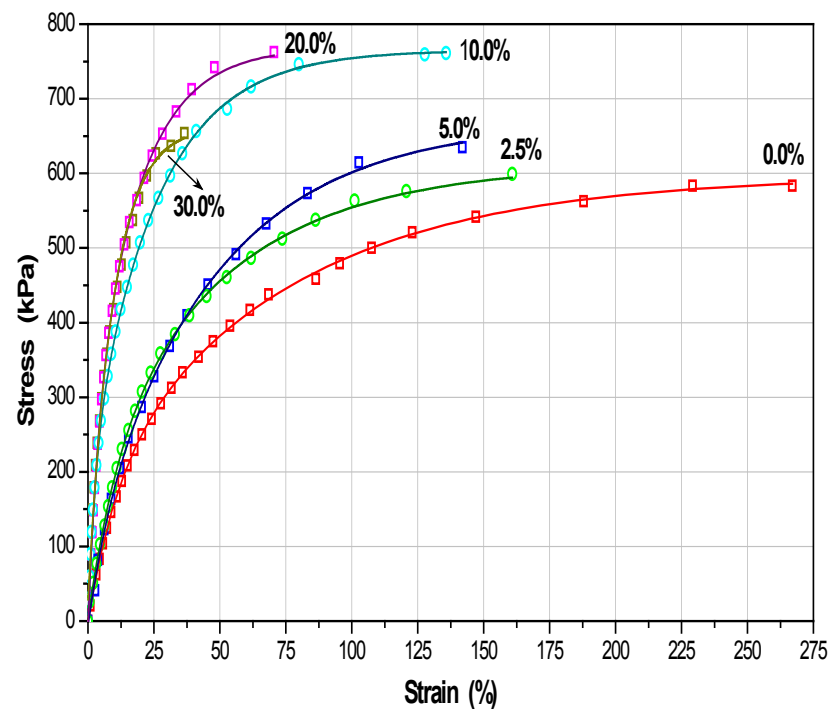

(b)

Figure 7. (a) Photograph of the graphite powder obtained by milling of the electrode; (b) Stress-strain curves of the elastomeric PU/GR composites with different filler content. 


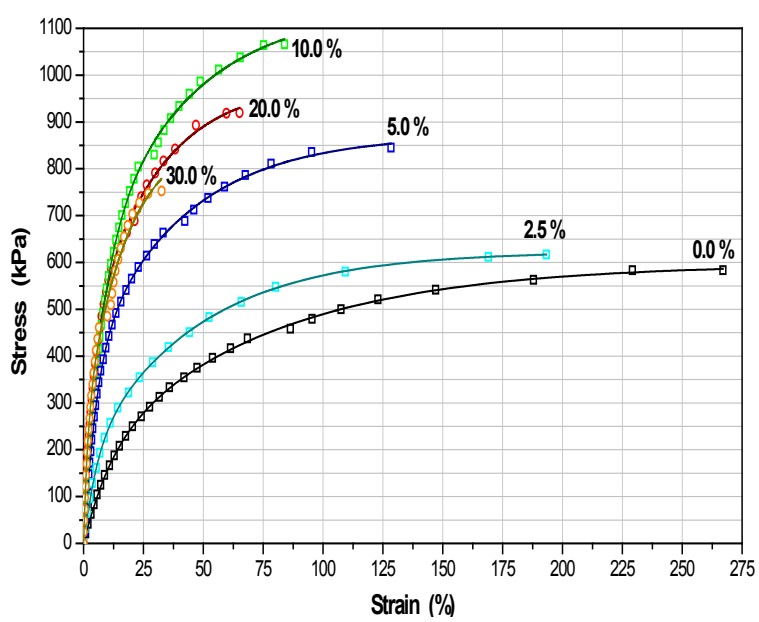

(a)

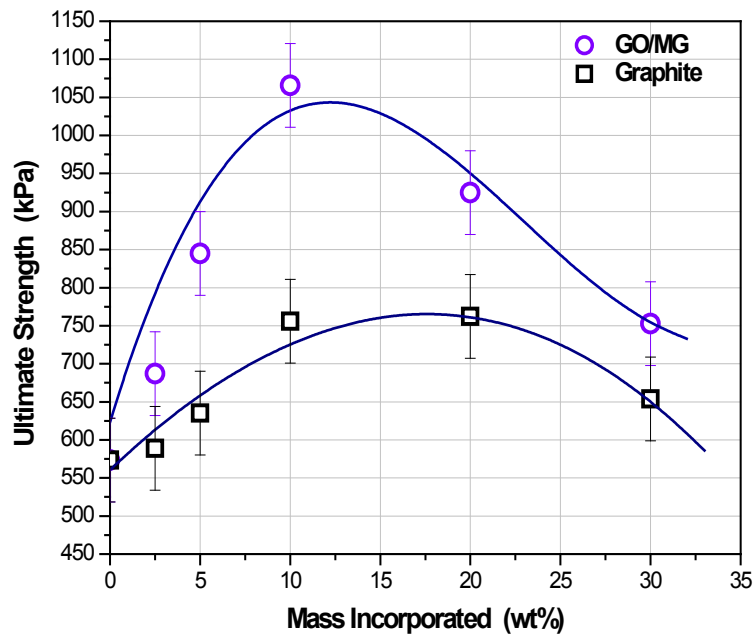

(b)

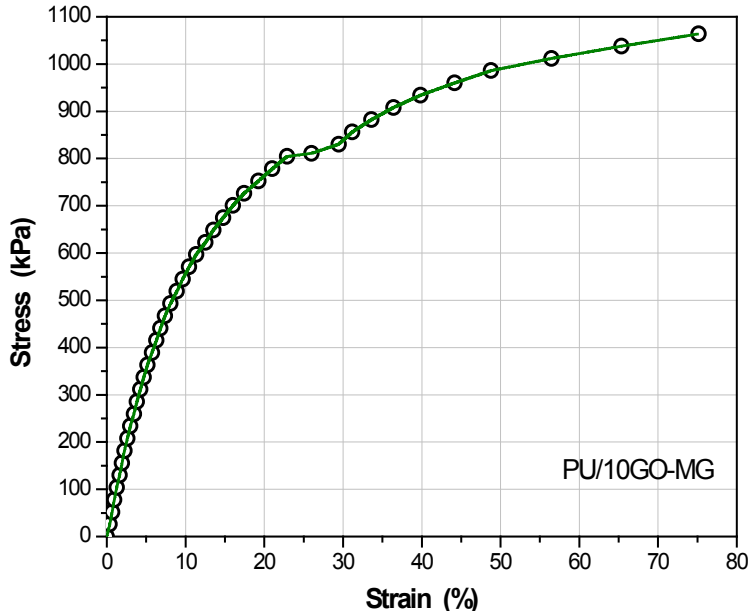

(c)

Figure 8. (a) The stress-strain curves of the elastomeric PU/GO-MG composites with different filler content; (b) The relationship between the breaking stress and the filler content; (c) Magnification of the stress-strain curve of the sample with $10 \mathrm{wt} \% \mathrm{GO}-\mathrm{MG}$ showing the presence of strain hardening. 
The distinctive stress-strain curves obtained from the PU/GO-MG composites is presented for just one composition in Figure $8(\mathrm{c})$. The results indicated that GO-MG fillers are capable of improving the breaking stress of elastomeric PU with the presence of strain hardening behavior [28]. The phenomenon of strain hardening in polymers is a consequence of orientation of molecular chains in the stretch direction. The large difference in mechanical properties between GR and GO-MG could be attributed to efficient load transfer between the graphene oxide sheets and the PU matrix, resulting from the covalent bonding and the cross-linking between the isocyanate chains and the functional groups attached to GO [13] [29], leading to the observed strain hardening behavior.

\section{Conclusions}

Exfoliated graphene oxide/multilayer-graphene (GO-MF) flakes were obtained by electrochemical exfoliation of industrial graphite performed in a two-electrode system using tungsten $(99.5 \% \mathrm{~W})$ as the counter electrode and graphite as the working electrode. From different analytical techniques and XRD results, it was concluded the presence of only these two structures: graphene oxide (GO) and multilayer-graphene (MG). It was calculated from XRD Rietveld refinement that flakes were approximately composed of $67 \mathrm{wt} \%$ GO and $33 \mathrm{wt} \%$ MG. Comparing Raman results with those reported previously, the number of layers in the graphene should be approximately between 2 and 5 sheets in our samples.

Besides, the relationship between the breaking stress of composites and type of filler content strongly suggests that the reinforcement contribution of graphite (GR) is not as effective as the one observed for graphene oxide/multilayer-graphene (GO-MG). The pure elastomeric PU showed a breaking stress of $570 \mathrm{kPa}$, while the PU/20GR attained a maximum stress of $750 \mathrm{kPa}$ as compared to PU/10GO-MF composite exhibiting a breaking stress of $1060 \mathrm{kPa}$. Finally, results indicated that GO-MG fillers are capable of improving the breaking stress of elastomeric PU by means of strain hardening behavior, probably improving orientation of molecular chains as a consequence of covalent bonding leading to cross-linking between the polymer and the functional groups attached to GO.

\section{References}

[1] Pierson, H.O. (1993) Handbook of Carbon, Graphite, Diamond and Fullerenes. Noyes Publications, Saddle River.

[2] Novoselov, K.S., Geim, A.K., Morozov, J.V., Jiang, D., Zhang, Y., Dubonos, S.V., Grigorieva, I.V. and Firsov, A.A. (2004) Electric Field Effect in Atomically Thin Carbon Films. Science, 306, 666-669. https://doi.org/10.1126/science.1102896

[3] Low, C.T.J., Walsh, F.C., Chakrabarti, M.H., Hashim, M.A. and Hussain, M.A. (2013) Electrochemical Approaches to the Production of Graphene Flakes and their Potential Applications. Carbon, 54, 1-21. https://doi.org/10.1016/j.carbon.2012.11.030

[4] Zhong, Y.L., Tian, Z. and Simon, G.P. (2015) Scalable Production of Graphene via Wet Chemistry: Progress and Challenges. Materials Today, 18, 73-78. https://doi.org/10.1016/j.mattod.2014.08.019 
[5] Bonaccorso, F., Lombardo, A., Hasan, T., Sun, Z., Colombo, L. and Ferrari, A.C. (2012) Production and Processing of Graphene and 2D Crystals. Materials Today, 15, 564-589. https://doi.org/10.1016/S1369-7021(13)70014-2

[6] Zhang, Y., Zhang, L. and Zhou, C. (2013) Review of Chemical Vapor Deposition of Graphene and Related Applications. Accounts of Chemical Research, 46, 2329-2339. https://doi.org/10.1021/ar300203n

[7] Reina, A., Jia, X., Ho, J., Nezich, D., Son, H., Bulovic, V., Dresselhaus, M. and Kong, J. (2009) Large Area Few-Layer Graphene Films on Arbitrary Substrates by Chemical Vapor Deposition. Nano Letters, 9, 30-35. https://doi.org/10.1021/nl801827v

[8] Becerril, H.A., Mao, J., Liu, Z., Stoltenberg, R.M., Bao, Z. and Chen, Y. (2008) Evaluation of Solution-Processed Reduced Graphene Oxide Films as Transparent Conductors. ACS Nano, 2, 463-470. https://doi.org/10.1021/nn700375n

[9] De Silva, K.K.H., Huang, H.H., Joshi, R.K. and Yoshimura, M. (2017) Chemical Reduction of Graphene Oxide Using Green Reductants. Carbon, 119, 190-199. https://doi.org/10.1016/j.carbon.2017.04.025

[10] Parvez, K., Wu, Z.S., Li, R., Liu, X., Graf, R., Feng, X. and Müllen, K. (2014) Exfoliation of Graphite into Graphene in Aqueous Solutions of Inorganic Salts. Journal of the American Chemical Society, 136, 6083-6091. https://doi.org/10.1021/ja5017156

[11] Su, C.Y., Lu, A.Y., Xu, Y., Chen, F.R., Khlobystov, A.N. and Li, L.J. (2011) High-Quality Thin Films from Fast Electrochemical Exfoliation. ACS Nano, 5, 2332-2339. https://doi.org/10.1021/nn200025p

[12] Li, L., Li, X., Du, M., et al. (2016) Solid-Phase Coalescence of Electrochemical Exfoliated Graphene Flakes into a Continuous Film on Copper. Chemistry of Materials, 28, 3360-3366. https://doi.org/10.1021/acs.chemmater.6b00426

[13] Yadav, S.K. and Cho, J.W. (2013) Functionalized Graphene Nanoplatelets for Enhanced Mechanical and Thermal Properties of Polyurethane Nanocomposites. Applied Surface Science, 266, 360-367. https://doi.org/10.1016/j.apsusc.2012.12.028

[14] Hu, K., Kulkarni, D.D., Choi, I. and Tsukruk, V.V. (2014) Graphene-Polymer Nanocomposites for Structural and Functional Applications. Progress in Polymer Science, 39, 1934-1972. https://doi.org/10.1016/j.progpolymsci.2014.03.001

[15] Parvez, K., Li, R., Puniredd, S.R., Hernandez, Y., Hinkel, F., Wang, S., Feng, X. and Müllen, K. (2013) Electrochemical Exfoliated Graphene as Solution-Processable, Highly Conductive Electrodes for Organic Electrodes. ACS Nano, 7, 3598-3606. https://doi.org/10.1021/nn400576v

[16] Ambrosi, A., Chua, C.K., Khezri, B., Sofer, Z., Webster, R.D. and Pumera, M. (2012) Chemically Reduced Graphene Contains Inherent Metallic Impurities Present in Parent Natural and Synthetic Graphite. Proceedings of the National Academy of Science of the United States of America, 109, 12899-12904.

https://doi.org/10.1073/pnas.1205388109

[17] Alam, S.N., Sharma, N. and Kumar, L. (2017) Synthesis of Graphene Oxide (GO) by Modified Hummers Method and Its Thermal Reduction to Obtained Reduced Graphene Oxide (rGO). Graphene, 6, 1-18. https://doi.org/10.4236/graphene.2017.61001

[18] Stobinskia, L., Lesiaka, B., Malolepszyc, A., Mazurkiewiczc, M., Mierzwaa, B., Zemekd, J., Jiricekd, P. and Bieloshapka, I. (2014) Graphene Oxide and Reduced Graphene Oxide Studied by the XRD, TEM and Electron Spectroscopy Methods. Journal of Electron Spectroscopy and Related Phenomena, 195, 145-154. https://doi.org/10.1016/j.elspec.2014.07.003

[19] Cai, M., Thorpe, D., Adamson, D.H. and Schniepp, H.C. (2012) Methods of Gra- 
phite Exfoliation. Journal of Materials Chemistry, 22, 24992-25002. https://doi.org/10.1039/c2jm34517j

[20] Marcano, D.C., Kosynkin, D.V., Berlin, J.M., Sinitskii, A., Sun, Z., Slesarev, A., Alemany, L.B., Lu, W. and Tour, J.M. (2010) Improved Synthesis of Graphene Oxide. ACS Nano, 4, 4806-4814. https://doi.org/10.1021/nn1006368

[21] Thangappan, R., Kalaiselvam, S., Elayaperumal, A. and Jayavel, R. (2014) Synthesis of Graphene Oxide/Vanadium Pentoxide Composite Nanofibers by Electrospinning for Supercapacitors Applications. Solid State Ionics, 268, 321-325. https://doi.org/10.1016/j.ssi.2014.10.025

[22] Zhou, Y., Bao, Q., Ling, L.A., Zhong, Y. and Loh, K.P. (2009) Hydrothermal Dehydration for the Green Reduction of Exfoliated Graphene Oxide to Graphene and Demonstration of Tunable Optical Limiting Properties. Chemistry of Materials, 21, 2950-2956. https://doi.org/10.1021/cm9006603

[23] Khan, M., et al. (2015) Green Approach for the Effective Reduction of Graphene Oxide Using Salvadora Persica Root Extract. Nanoscale Research Letters, 10, 281-291. https://doi.org/10.1186/s11671-015-0987-Z

[24] Wang, G., Wang, B., Park, J., Yang, J., Shen, X. and Yao, J. (2009) Synthesis of Enhanced Hydrophilic and Hydrophobic Graphene Oxide Nanosheets by a Solvothermal Method. Carbon, 47, 68-72. https://doi.org/10.1016/j.carbon.2008.09.002

[25] Lai, Q., Zhu, S., Luo, X., Zou, M. and Huang, S. (2012) Ultraviolet-Visible Spectroscopy of Graphene Oxides. AIP Advances, 2, Article ID: 032146.

[26] Yang, D., et al. (2009) Chemical Analysis of Graphene Oxide Films after Heat and Chemical Treatments by X-Ray Photoelectron and Micro-Raman Spectroscopy. Carbon, 47, 145-152. https://doi.org/10.1016/j.carbon.2008.09.045

[27] Ferrari, A.C., Meyer, J.C., Scardaci, V., Casiraghi, C., Lazzeri, M., Mauri, F., Piscanec, S., Jiang, D., Novoselov, K.S., Roth, S. and Geim, A.K. (2006) Raman Spectrum of Graphene and Graphene Layers. Physical Review Letters, 97, Article ID: 187401. https://doi.org/10.1103/PhysRevLett.97.187401

[28] Bower, D.I. (2002) An Introduction to Polymer Physics. Cambridge University Press, Cambridge.

[29] Cai, D., Yusoh, K. and Song, M. (2009) The Mechanical Properties and Morphology of a Graphite Oxide Nanoplatelet/Polyurethane Composite. Nanotechnology, 20, Article ID: 085712. https://doi.org/10.1088/0957-4484/20/8/085712 